DOI: http://doi.org/10.52716/jprs.v11i2.497

\title{
3D Reservoir Rock Type Model Based on Cluster Analysis Technique for Rumaila Formation in the Ahdeb Oil Field, Central Iraq
}

\author{
Buraq Adnan Hussein Al-Baldawi \\ Department of Geology, College of Science, University of Baghdad. Baghdad- Iraq \\ Author E-mail: Buraqadnan81@ gmail.com
}

Received 11/11/2020, Accepted 19/1/2021, Published 20/6/2021

This work is licensed under a Creative Commons Attribution 4.0 International License.

\begin{abstract}
$\underline{\text { Abstract: }}$
This study presents is a classification of reservoir properties (porosity and shale volume) into rock types for carbonate Rumaila reservoir in Central Iraq (Ahdeb Field). The Cluster analysis method is used to identify rock types and to recognize well log clusters of similar characteristics. For most subsurface research, the determination of the rock type (lithofacies and petrofacies) is not adequate enough because of a lack of cores and cuttings. An interactive petrophysics software program was used to get the results of a cluster analysis technique, in order to determine the rock typing (log facies) in Rumaila formation units in the Ahdeb oil field. Initially, petrophysical parameters such as porosity, shale volume and quantity of various reservoir minerals were determined using the probabilistic evaluation process. In the second stage, the multiresolution graphic clustering method was employed to separate the sequential electrofacies which resulted in the identification of four electrofacies with different geological reservoir properties. The vertical variations of the rock type for Rumaila formation are based on four log facial groups. These log groups are categorized according to porosity and shale volume of formation based on responses to well logs after division of Rumaila formation into four units (Ru-1, Ru-2, Ru-3, and Ru-4).A 3D rock type model for Rumaila Formation was performed using Petrel software in order to illustrate the horizontal distribution of rock type along the Ahdeb field and showing the best characterized of reservoir rock type in any unit of Rumaila Formation. Cluster analysis technique classified porosity and shale volume, which were calculated for Rumaila Formation using well logs, into four similar characteristics rock types: rock
\end{abstract}




\section{Journal of Petroleum Research and Studies}

Open Access

No. 31, June 2021, pp.49-73

type-1, rock type-2, rock type-3 and rock type-4. A 3D Petrel model of rock type shows that rock type- 2 has better reservoir quality than other rock types in Rumaila Formation which is characterized by high porosity and low shale volume. The model clarifies the distribution of rock type- 2 in the Ahdeb field at units $\mathrm{Ru}-1$ and $\mathrm{Ru}-3$ of Rumaila Formation.

Key Words: Logfacie, Rumaila Formation, Ahdeb Field, Cluster Analysis.

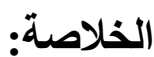
تمثل هذه الدراسة تصنيف الصفات المكمنية مثل المسامية المكمنية وحجم الاطيان (السجيل) الى أصناف مختلفة

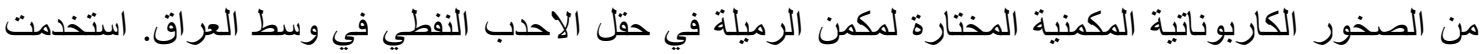

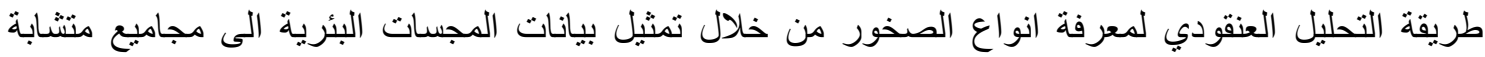

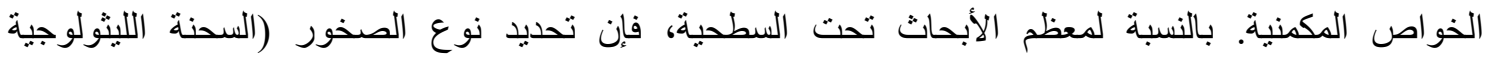

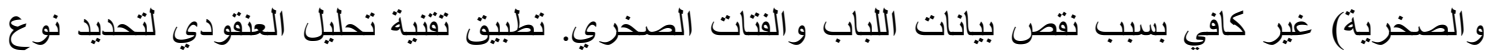

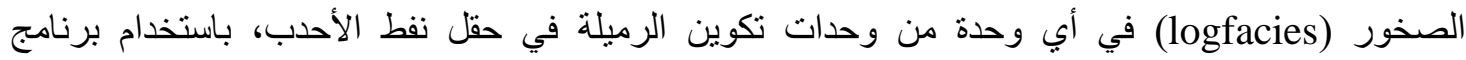
interactive petrophysics معادن المكمن المختلفة باستخدام عملية التقييم الاحتمالية.

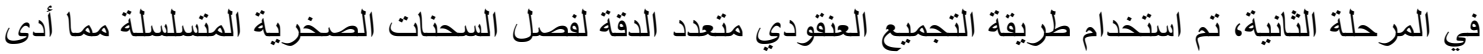

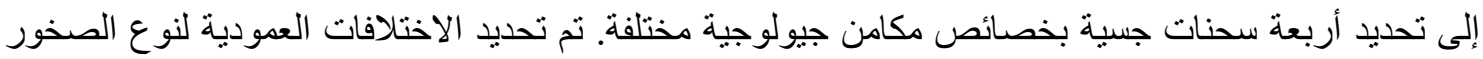

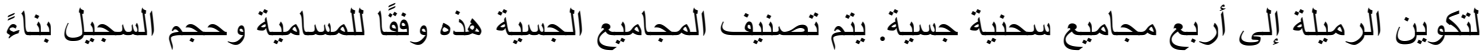

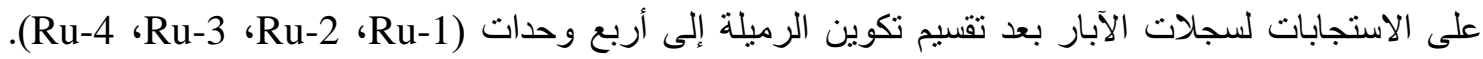

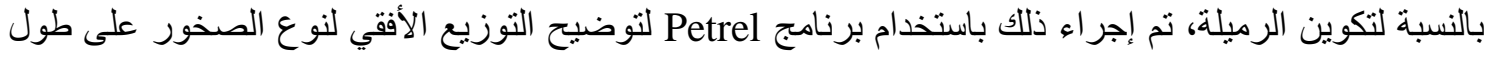
حقل Ahdeb و إظهار أفضل أنواع الصخور المكمنية في أي وحدة من وحدات تكوين الرميلة. صنفت تقنية التهبة التحليل

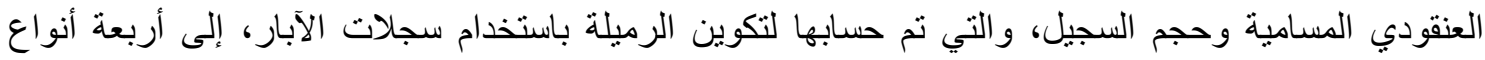

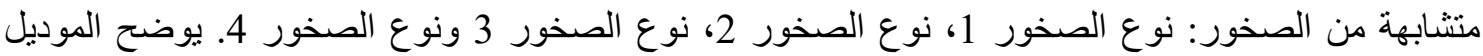

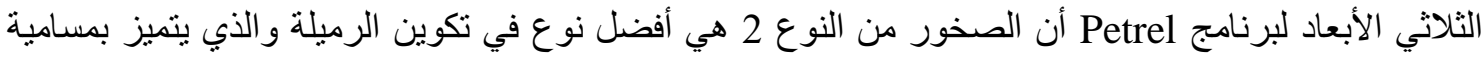

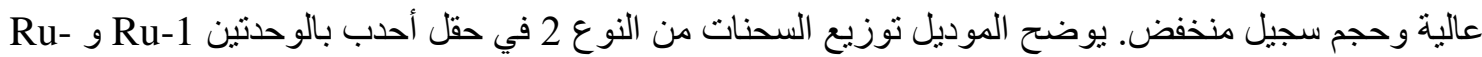

3 من تكوين الرميلة.

\section{Introduction}

Logs are essential sources of geological sub-surface exploration. Well logs provide valuable information on composition, texture, petrophysical characteristics and sedimentary structures, including porosity and permeability. Through gathering data from specific logs, distinguishable geologic units with the same log attributes were 


\section{Journal of Petroleum Research and Studies}

Open Access

No. 31, June 2021, pp.49-73

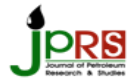

P- ISSN: 2220-5381

E- ISSN: 2710-1096

identified. The sedimentary units identified on this basis and characterized by cable logs are known in the literature as electrofacies or logfacies [1].

The most important tools for research on crude oil, depositional basin are the rock type and $\log$ facies analysis, particularly when accurate information is only available on wireline logs. Rock type analysis can be carried out manually or automatically using mathematical methods. One of the most reliable and affective approaches to oil storage in a reservoir is a multi-varian cluster analysis (as the best data grouping method). This technique is used with both detrital and carbonate rocks [2].

The determination of the kind of reservoir rock type is the most important activity in the oil industry and relies mainly on the essential characteristics of rocks. Specific rock properties are usually known in a detailed field definition (lithofacies evaluation) and in the laboratory (petrofacies study) [3].

The purpose of well log cluster analysis is to look for similarities/dissimilarities between data points in the multivariate space of logs, in order to group them into classes also called electrofacies.

The clusters analysis defines electrofacies on the basis of the unique characteristics of well log measurements reflecting minerals and lithofacies within the logged interval [4]. The classification of well logs not includes a synthetic division of the set of data, but it follows normally the specific characteristics of log-based measurement data representing minerals and lithofacies within the logged interval.

Tthe vertical variations of logfacies for Khasib Formation are carried out based on five groups of logfacies. These groups of logfacies are classified based on responses of well logs after divided Khasib Formation into three units: (upper, middle and lower Khasib) [5].

In this study, Interactive Petrophysics program V4.4 made this classification. Furthermore, the horizontal and vertical distributions of rock types in Ahdeb Oil Field for Rumaila Formation are carried out on the basis that these clusters are classified into four classes of rock type. Rumaila Formation has been selected from the ten Ahdeb 


\section{Journal of Petroleum Research and Studies}

Open Access

No. 31, June 2021, pp.49-73

Area (AD-1, AD-2, AD-3, AD-5, AD-9, AD-11, AD-12, AD-13, AD-14, and AD-15) as a carbonate reservoir penetrating and uniformly distributing it in a carbonate reservoir for units of rock type. In order to obtain presence and distributed rock types based on cluster analysis, Petrel software is used to implement the 3D rock type model per area of Rumaila Formation.

\section{Geological and Structural Background:}

The Ahdeb field is located between Nomina and Wasit cities, in central Iraq, 180 kilometers South-East of Baghdad [6] in Figure (1). The petroleum field is located in the river plain between the Euphrates and the Tigris. The field is situated in the central region of Mesopotamia according to Iraq's tectonic zones. It is situated on the northeast edge of the Arab plate, on the Arabian platform inside an intra-platform basin. The Ahdeb oil field is the NWW-SEE anticlinal structure. It is distinguished by two small, low-amplitude NW-SE rising crests (the south dome, with a wide spread) and three structural crests along its length referred to as the AD-1 at the north dome and divided into the two AD-2 crests and the AD-4 crests separated by the saddles. There is no fault in this area above Mauddud Formation. The dip angle from the south side of the anticline is 0.7 to -0.9 to the south, the dip angle from the north side is 2 to the south side, and the north limb is more moving than the south limb [8].

The Ahdeb oil field consists of several reservoir formations comprising major oilbearing formations in the Ahdeb region: Khasib Formation of the upper Cretaceous, Mishrif, Rumaila and Mauddud of the Middle Cretaceous formations. Based on the study of the possible test performed in exploration wells. Horizontally, Khasib petroleum bearings are spread throughout the region, while Mishrif, Rumaila and Mauddud oil - bearing formations are mostly spread in the eastern area in Figure (2). The Rumaila formation is the most common Cenomanian group in middle and southern Iraq. It was initially identified from the Zubair wells of the Mesopotamian region [10]. 
In the area of type, the formation includes fine, marly, oligosteginal limestone with marbles, which fall into fine grain, limestone calystone below [11]. The formation in the type area usually is $90 \mathrm{~m}-120 \mathrm{~m}$ thick. The top portion of the Ahdeb oil field rumaila formation primarily consists of red, brown, brownish white, soft-hard calestone, interspersed with thin clay calestone. The middle and bottom parts are brownish gray, porous calcareous sediments off-white to red [12].

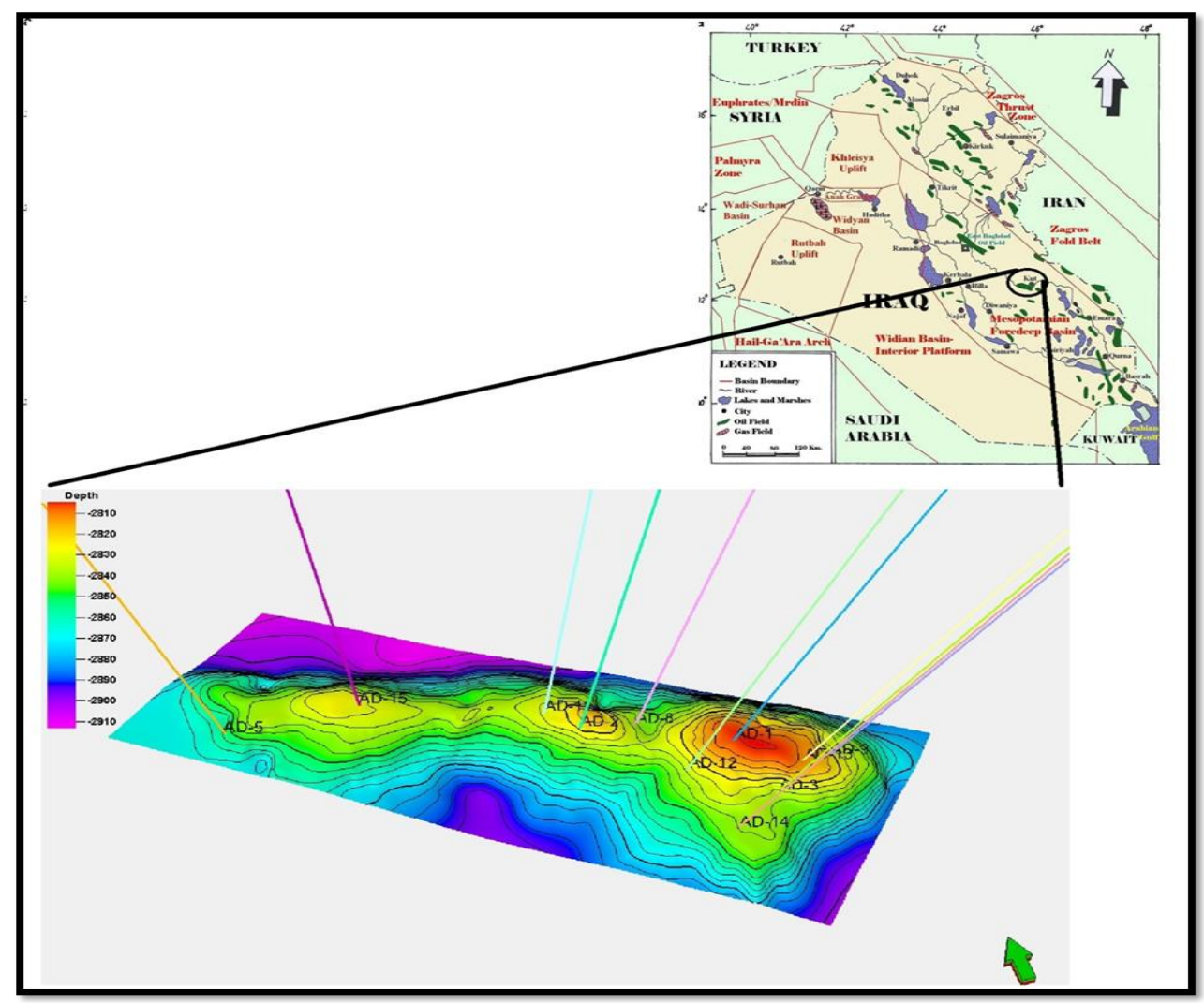

Fig. (1) Location map of the study area. [7] with the structural contour map of Rumaila Formation in Ahdeb Oil field which is built by author. 
Open Access

No. 31, June 2021, pp.49-73

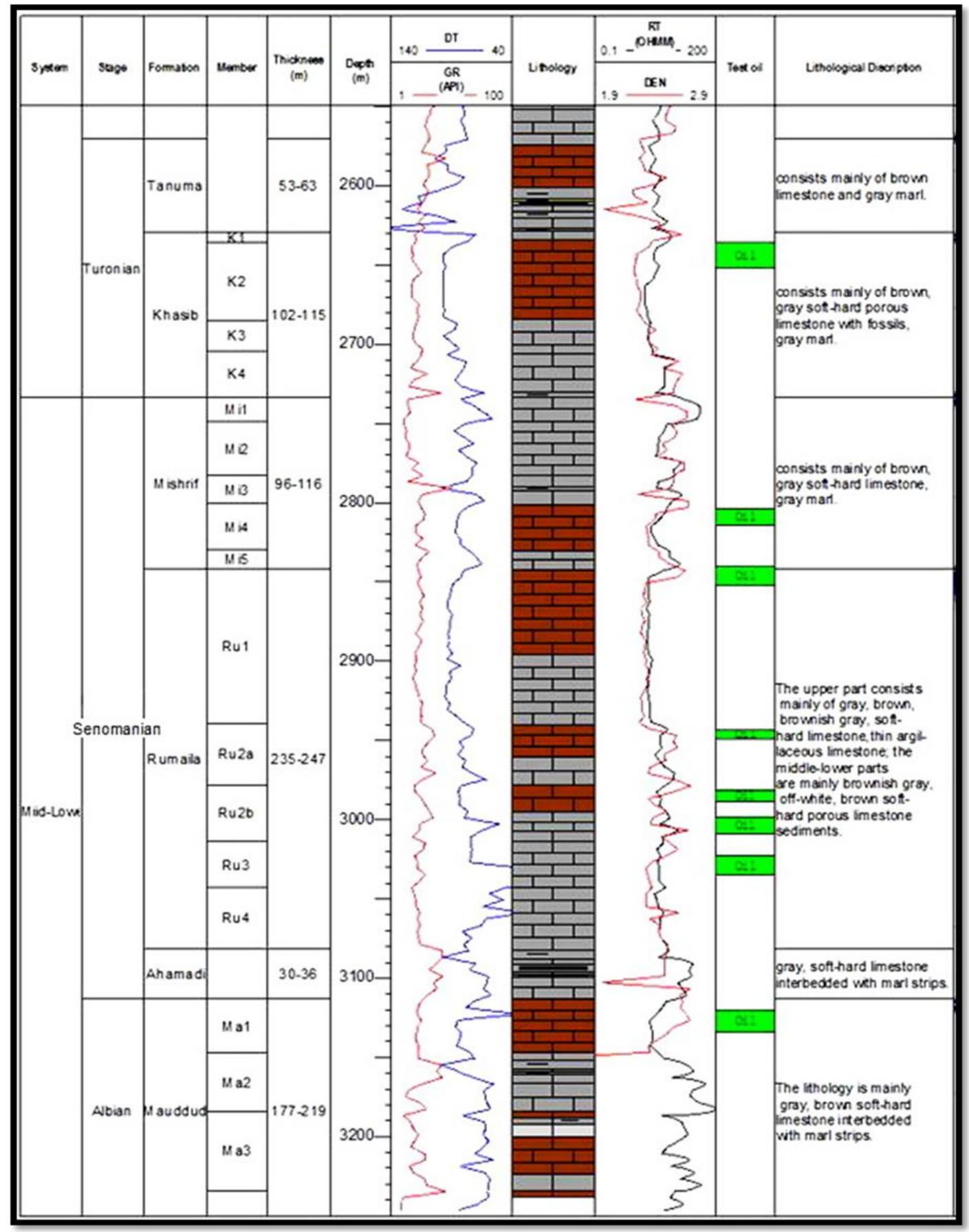

Fig. (2) Stratigraphic Column of the Ahdeb oil field in well AD-1 [9]. 


\section{Journal of Petroleum Research and Studies}

Open Access

No. 31, June 2021, pp.49-73

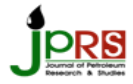

P- ISSN: 2220-5381

E- ISSN: 2710-1096

\section{Methodology:}

This study included analysis of lithological properties based on data derived from the open hole logs of wells under research such as gamma, density and neutron logs using of cluster analysis. The software Neuralog has been used to digitize the logs. One reading per $0.25 \mathrm{~m}$ of depth is chosen to record the measurements of input data used in this analysis. Using interactive petrophysics (IP) tools, environmental corrections and interpretations of well logs were carried out and designed for evaluating cluster properties of Rumaila Formation. After the results of cluster analysis were exported to Petrel, Petrel software was used to build the model of a 3D reservoir of rock type.

\section{Experimental Works}

\subsection{Clustering Procedure:}

Different log responses can arise because of several factors affecting the logs. Data are clustered into a minimum distance and maximum homogeneity during the clustering stage since the use of statistical processes is compulsory. It is evident that a collection of data, such as rock type, can be used by geologists to further examine various geological parameters. Both log readings for this calculation are known as "observations" and logs used as the "values of observations"[13].

The smallest distances are linked to a pair in cluster analysis. The number of rock type is normally less than the number of readings, since vector pairs (log readings couples) have been combined to form a cluster. In order to build higher classes, the lower classes are related. This procedure goes on until a single cluster has been generated (which represents the entire data). Two clusters are related by different methods. Any of these are related by the minimum distance of the components of the clusters. The two-stage clustering module used in interactive petrophysics software (IP) is divided into handling data clusters. First, information (porosity and shale volume). The number of clusters should be sufficient enough to cover the various data sets in the logs. In most data sets, 
15 to 20 clusters tend to be a decent number. The second and more manual step is to group these 15-20 clusters into a number of geological faces that are achievable. This may involve reducing the data to four groups identified by four rock types.

The important data used in the clustering model is porosity and shale volumes which are measured based on data from well logs imported into software Interactive Petrophysics. Estimate of the gamma ray index is the first stage in evaluating the shale volume of a gamma ray log; [14] is used for old rocks:

$$
I G R=\frac{\text { GRlog- GRmin }}{\text { GRmax- GRmin }}
$$

The shale volume was computed by using the following [15] formula

$$
V s h=0.33 *\left(2^{2 * I G R}-1\right)
$$

Where

IGR = gamma ray index.

GRlog= gamma ray reading by $\log (A P I)$.

GRmin $=$ minimum gamma (clean sand or carbonate).

GRmax = maximum gamma ray (shale).

Vsh $=$ volume of shale .

The neutron and density calculation combination is the most common This provides a more precise porosity, commonly used for the calculation of the mean neutron density porosity $\Phi$ ND. This combination is called the total porosity (total porosity), which is the overall volume of voids [16, 17]. The combination formula is

$\Phi \mathrm{N} . \mathrm{D}=\frac{\Phi \mathrm{N}+\Phi \mathrm{D}}{2}$

Фe can be computed by the following equation [18] that used in the current study.

$\Phi \mathrm{e}=\Phi \mathrm{t} \times(1-\mathrm{VSh})$

Where

$\Phi N . D=$ neutron and density porosities combination (total porosity $\Phi \mathrm{t}$ ).

$\Phi \mathrm{N}=$ neutron porosity.

$\Phi \mathrm{D}=$ density porosity. 


\section{Journal of Petroleum Research and Studies}

Open Access

No. 31, June 2021, pp.49-73

$\Phi \mathrm{e}=$ effective porosity.

The clustering module carried out in two stages using Interactive Petrophysics software (IP): Firstly, the data (effective porosity and shale volume) are divided up into manageable data clusters. The number of clusters should be enough to cover all the different data ranges seen on the logs. Fifteen to 20 clusters would appear to be a reasonable number for most data sets. The second step, which is more manual, is to take these 15 to 20 clusters and group them into a manageable number of geological facies. This may involve reducing the data to four clusters

A first step of 'rock clustering' is using K-mean statistical techniques to cluster data into a known number of clusters attempted to enter by using comprehensive logs to determine porosity and shale thickness. Initially, for each input log, the average value of each cluster must be determined. Original measurement influences outcomes. For reasonable results, the initial values should cover the entire log range. K-mean clustering works by assigning a cluster to each input level. This approach aims to reduce the internal cluster square gap from data point to cluster mean [19]. This loop continues until the mean values between loops do not change. Such are the outcomes. Before beginning, all log data is standardized and each log input has the same dynamic range. Normalization is done by measuring the log's average and standard deviation and then normalizing the data by extracting the mean and separating it into the standard deviation.

\subsection{Cluster Consolidation:}

Cluster aggregation can be achieved entirely by using the results for group data from the cross plot and log plot using the hierarchy technique of data grouping. Hierarchical clustering operates by calculating distances between all clusters and fusing them closely. The next two clusters combine. The current cluster distance has been republished. The loop continues until there is one cluster. Prüfungen can be represented as a dendrogram. The dendrogram indicates how clusters were grouped and merged. 
The top numbers of each branch give the order of merge. Initial K-mean is checking. IP has five different approaches to clustering to assess whether clusters have merged which are:

1. Minimum distance between all objects in clusters - the distance from $\mathrm{Z}$ to $\mathrm{C}$ is the minimum of the distances ( $\mathrm{A}$ to $\mathrm{C}$ and $\mathrm{B}$ to $\mathrm{C}$ as shown in Figure (3))

2. Maximum distance between all objects in clusters - the distance from $\mathrm{Z}$ to $\mathrm{C}$ is the maximum of the distances ( $\mathrm{A}$ to $\mathrm{C}$ and $\mathrm{B}$ to $\mathrm{C}$ ).

3. Average distance between merged clusters - the distance from $\mathrm{Z}$ to $\mathrm{C}$ is the average distance of all objects that would be within the cluster formed by merging clusters and C.

4. Average distance between all objects in clusters - the distance from $\mathrm{Z}$ to $\mathrm{C}$ is the average distance of objects within cluster $\mathrm{Z}$ to objects within cluster $\mathrm{C}$.

5. Minimize the within-cluster sum of squares distance- clusters are formed so as to minimize the increase in the within-cluster sums of squares. The distance between the two clusters is the increase in these sums of squares if the two clusters were merged.

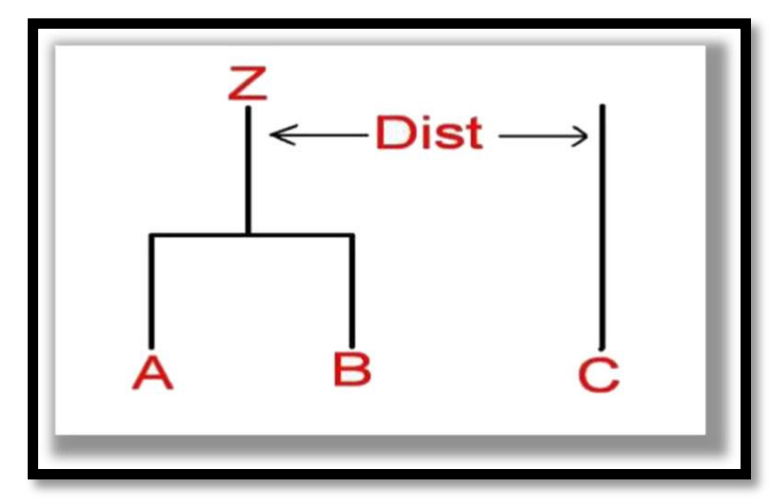

Fig. (3) Dendrogram plot shows distance between clusters (A, B, and C).

The default method 'Limit the in-cluster square distance number' produces good results in separating the different types of log rock from clusters as shown in Figure (4). The clusters are grouped into a known number of groups by stopping the grouping at a 
certain interruption point. Groups may be evaluated to decide which level to add a particular cluster provides more information or only adds noise. This information is given in the 'Cluster Randomness Plot', Figure (5).

The randomness is determined first by calculating the average number of depth levels per cluster - i.e. the average cluster thickness. It is achieved with the original log data. The theoretical average thickness is then estimated to conclude that the clusters are randomly distributed at each depth level. Randomness is the interaction between the two. A 1 value would be entirely random, higher values would be less random.

Av. Thickness $=$ Number of depth levels $/$ Number of cluster layers

Random Thickness $=\Sigma \mathrm{p}_{i} /\left(1-\mathrm{p}_{i}\right)$

Where; $\mathrm{p}_{i}$ is the proportion of the depth of the ith cluster allocated.

Randomness index $=$ Av. Thickness $/$ Random Thickness

The plot is represented by choosing the least random numbers of clusters (highest points).

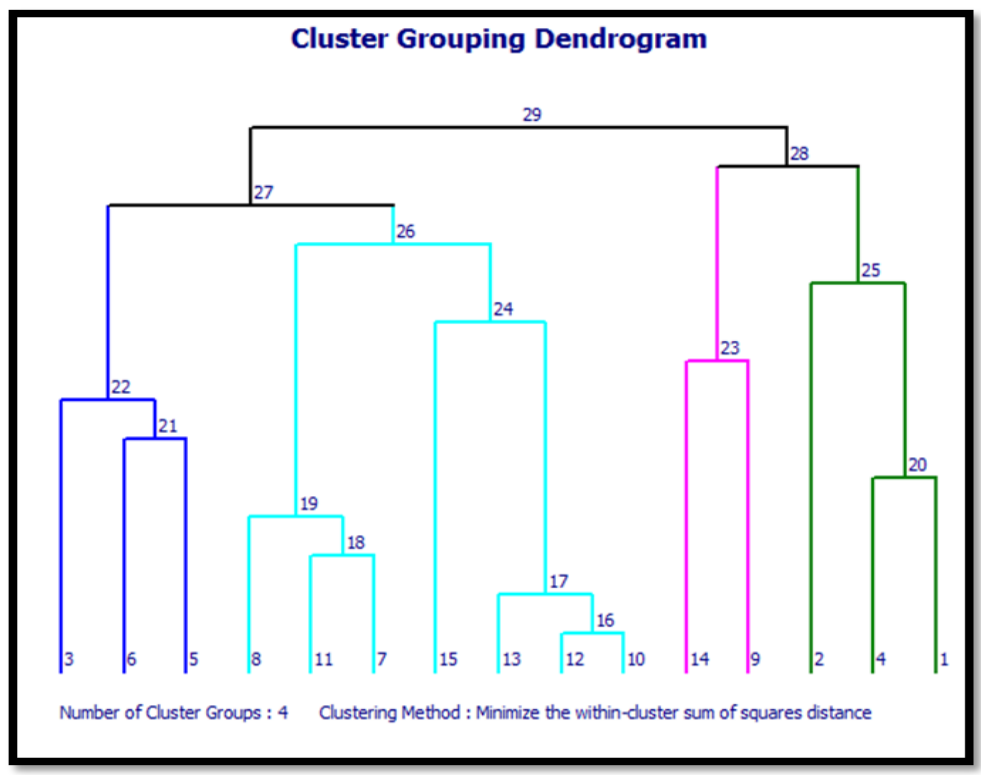

Fig. (4) Dendrogram plot shows distribution of the fifteenth clusters with its groups. 


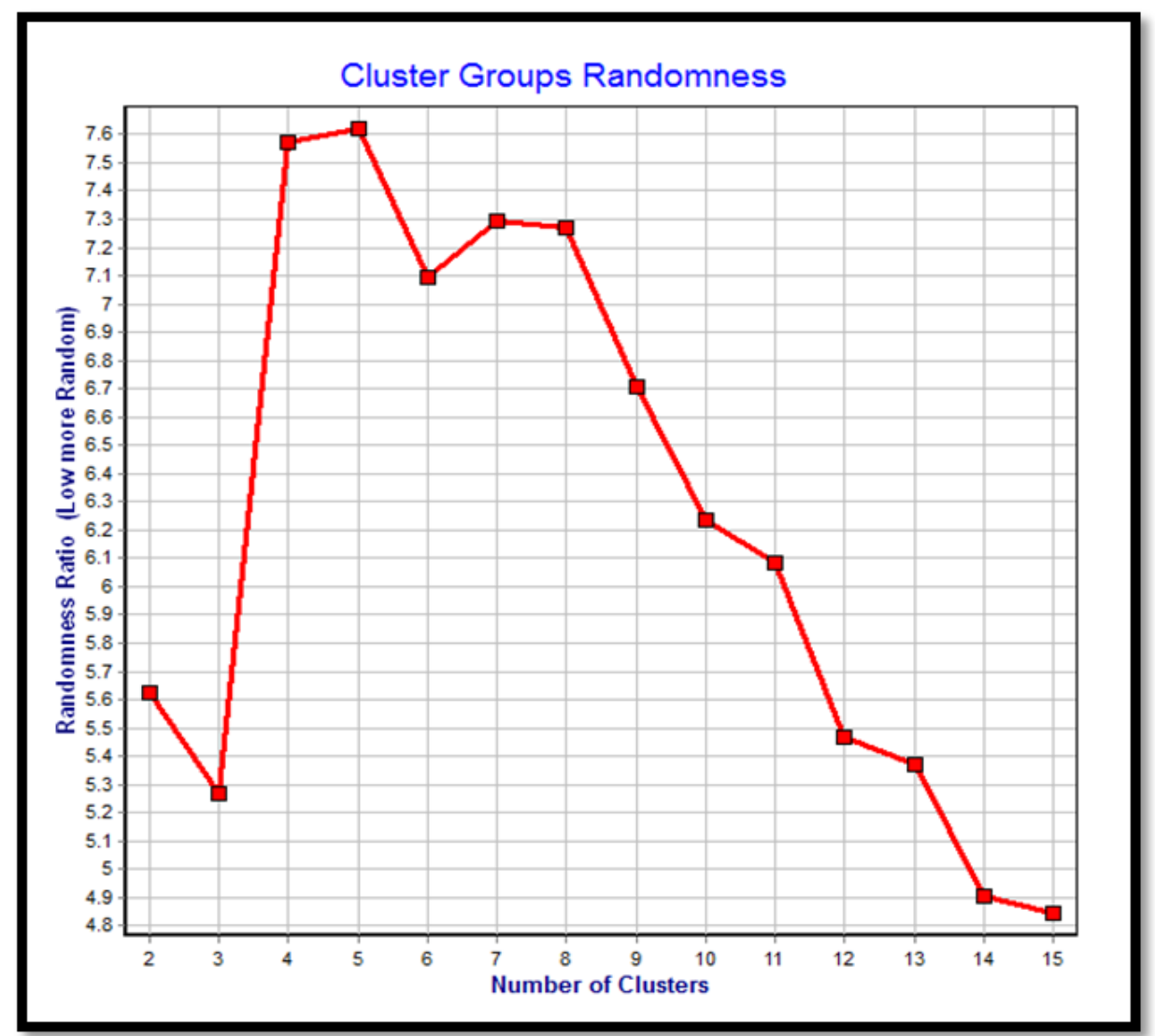

Fig. (5) Cluster randomness plot shows the relation between number of clusters and randomness Ratio.

\subsection{Petrel Model}

The goal of this project is to create a 3D rock model for the Rumaila formation in the Ahdeb region using software from Petrel after cluster analysis of the technique vertical distribution of rock types is performed. The key steps in constructing a 3D model of a petroleum reservoir using petrel software are the following: The structure, layer and reservoir properties (X, Y and Z).

1-Data Control, including:

Georeferencing. Georeferencing.

Import of data that includes hands, well logs, rock forms, and well tops. 
Editing and quality control of input data (Q.C).

2-Model of stratigraphy.

3-Structural modeling, including:

Floor gridding. Floor gridding.

Make horizons, make horizons.

Layering. Layering.

4-Modeling of properties, which includes:

Scale logs up well.

Modeling of facies (model type of rock).

\subsection{D rock types (log-facies) model}

One of the most critical tasks of reservoir design is the protection of the key geological features and heterogeneities in the reservoir. In certain cases the modeling of facies of reservoirs is the most critical aspect of reservoir modeling as the rock type can be the main control factor of reservoir heterogeneity. If rock modeling technology has been used, the geometry and distribution of key facies and petrophysical properties in the facies must also be generated and populated.

Modeling rock type is a way of spreading distinct rock form around the model grid. Typically, by analyzing this data in the process data analysis phase, the processor would have up-scaled logs with discreet properties in the model grid and theoretically identified patterns within the reservoir (Fig.6). In this study, the 3D rock type model of Rumaila Formation is constructed from study of main rock types which are deduced using well logs data by cluster analysis technique.

After making layering for reservoir units for Rumaila Formation, the layers for each reservoir unit is recognized with specific Rock type. Petrel provides several algorithms for modeling rock type distribution in a reservoir environment Sequential indicator Simulation Algorithm is used as a statistical tool for creating a model type that suits the 
amount of available data. Initially, data processing was carried out to measure standard score transformations and experimental variogram ranges.

\section{4. $\underline{\text { Results and Discussions }}$}

The results of this study showed cluster technique has identified four key electrofacies with different levels of four rock types which have been predicted from this technique. The k-mean clustering analysis was the most accurate method where each predicted electrofacies reflects the same vertical distribution of the lithofacies in the reservoir. On the other hand, the Ward's Hierarchical electrofacies prediction represents specific petrophysical properties with minor differences from real lithofacies distribution in the reservoir. The Rumaila Formation according to the dendrogram shown in Figure (4) is divided into 15 clusters and subsequently grouped into four groups, classifying them based on match or difference between groups.

Each cluster is characterized by average shale volume and porosity measurements. Table (1) displays the results of "Cluster Means," which display the mean values plus other statistics for the data used by each cluster (15 clusters). After classifying the data used in 15 clusters, these clusters were used to create groups of rock types. Rumaila Training has been divided into four groups. The group of logfacies has a well-log answer, and each group can contain one or more clusters. Figure (6) shows histograms and cross-plots for the Rumaila Formation groups between the wells used as generated by a k-means cluster analysis. Researchers in [20] were built four rock types and groups which are identified in the Yamama formation depending on the FZI method but in the current study, four rock types were defined and distributed vertically and horizontally among the 10 wells examined depending on Cluster Analysis Technique as shown in Figures (8) and (9).Each rock type is characterized by response of porosity and shale volume as well as microfacies type: 


\section{Rock Type-1}

Represents poor to moderate rock types (blue); effective porosity is 0.04 to 0.1 and less than 30 percent of shale volume. This form represents a good reservoir quality and matches the style of microfaces (wackestone).

\section{Rock Type-2}

It is perfect for a very good form of calcareous rock (Aqua colour) in which the effective porosity is greater than $15 \%$ and the shale volume is less than $35 \%$. This form represents the ideal reservoir quality and corresponds to the class of microfaces (packstone to grainstone).

\section{Rock Type-3}

This contains fair to strong calcareous rocks, with effective porosity varying from 0.15 to $0.25 \%$ but shale volume approaching $45 \%$. This type of rock represents a moderate quality in the reservoir and coincides with the type of microfaces.

\section{Rock Type-4}

The poor (green) one has an effective porosity of less than 0.1 and shale of more than $45 \%$. This type of rock represents a weak reservoir quality and is associated with bad microfaces.

The 3D rock type model was built for each unit of Rumaila Formation after import all rock types into petrel software in order to shows the horizontal and vertical distribution of rock type along of Ahdeb domes. 
Journal of Petroleum Research and Studies

Open Access

No. 31, June 2021, pp.49-73

Table (1) Cluster analysis results for each rock type

\begin{tabular}{|c|c|c|c|c|c|c|}
\hline \multirow{2}{*}{ Cluster } & \multirow{2}{*}{ Color } & \multirow{2}{*}{ Points } & \multicolumn{2}{|c|}{ VSH } & \multicolumn{2}{|c|}{ PHIE } \\
\hline & & & Mean & Std Dev. & Mean & Std Dev. \\
\hline 1 & & 593 & 0.40578 & 0.072 & 0.0174 & 0.0178 \\
\hline 2 & & 334 & 0.72806 & 0.1 & 0.0382 & 0.0401 \\
\hline 3 & & 639 & 0.15058 & 0.0587 & 0.0388 & 0.0246 \\
\hline 4 & & 545 & 0.49596 & 0.0604 & 0.0721 & 0.0219 \\
\hline 5 & & 1452 & 0.28904 & 0.0454 & 0.0883 & 0.0195 \\
\hline 6 & & 1590 & 0.14616 & 0.0494 & 0.1122 & 0.0162 \\
\hline 7 & & 1794 & 0.25648 & 0.035 & 0.148 & 0.016 \\
\hline 8 & & 1454 & 0.3929 & 0.0405 & 0.1493 & 0.0201 \\
\hline 9 & & 827 & 0.55143 & 0.06 & 0.1574 & 0.0179 \\
\hline 10 & & 1763 & 0.13879 & 0.0382 & 0.17 & 0.0139 \\
\hline 11 & & 1780 & 0.29453 & 0.037 & 0.2018 & 0.0168 \\
\hline 12 & & 2861 & 0.19107 & 0.0277 & 0.2069 & 0.014 \\
\hline 13 & & 2352 & 0.09536 & 0.0357 & 0.2156 & 0.0159 \\
\hline 14 & & 237 & 0.51522 & 0.119 & 0.2694 & 0.0354 \\
\hline 15 & & 972 & 0.23953 & 0.0592 & 0.2791 & 0.018 \\
\hline
\end{tabular}

\begin{tabular}{|l|l|l|l|}
\hline Rock Type-1 & Rock type-2 & Rock Type-3 & Rock Type-4 \\
\hline & & & \\
\hline
\end{tabular}


Journal of Petroleum Research and Studies

Open Access

No. 31, June 2021, pp.49-73

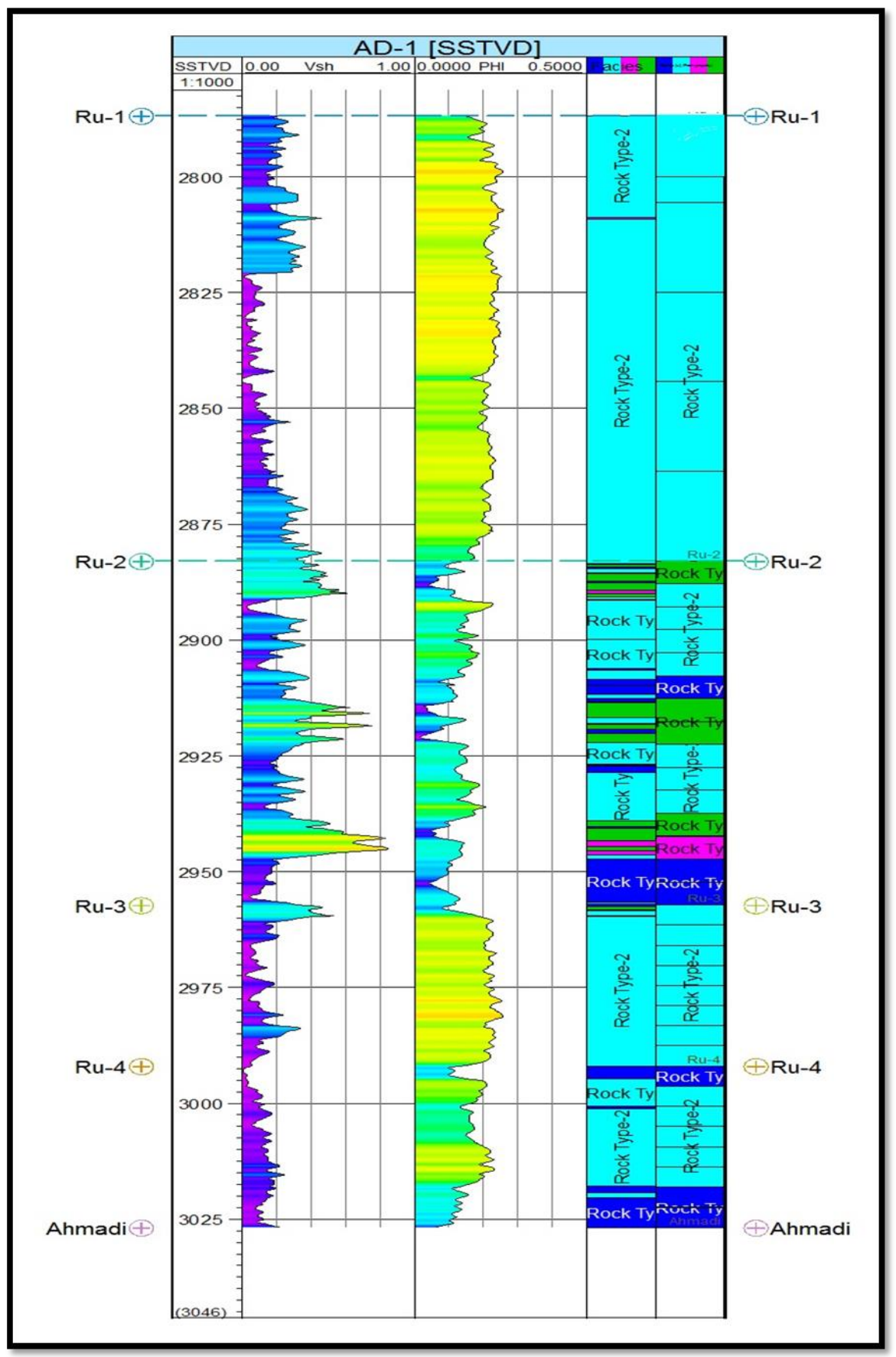

Fig. (6) Scale up of well logs for rock type model showing the average value of reservoir properties at well AD-1. 


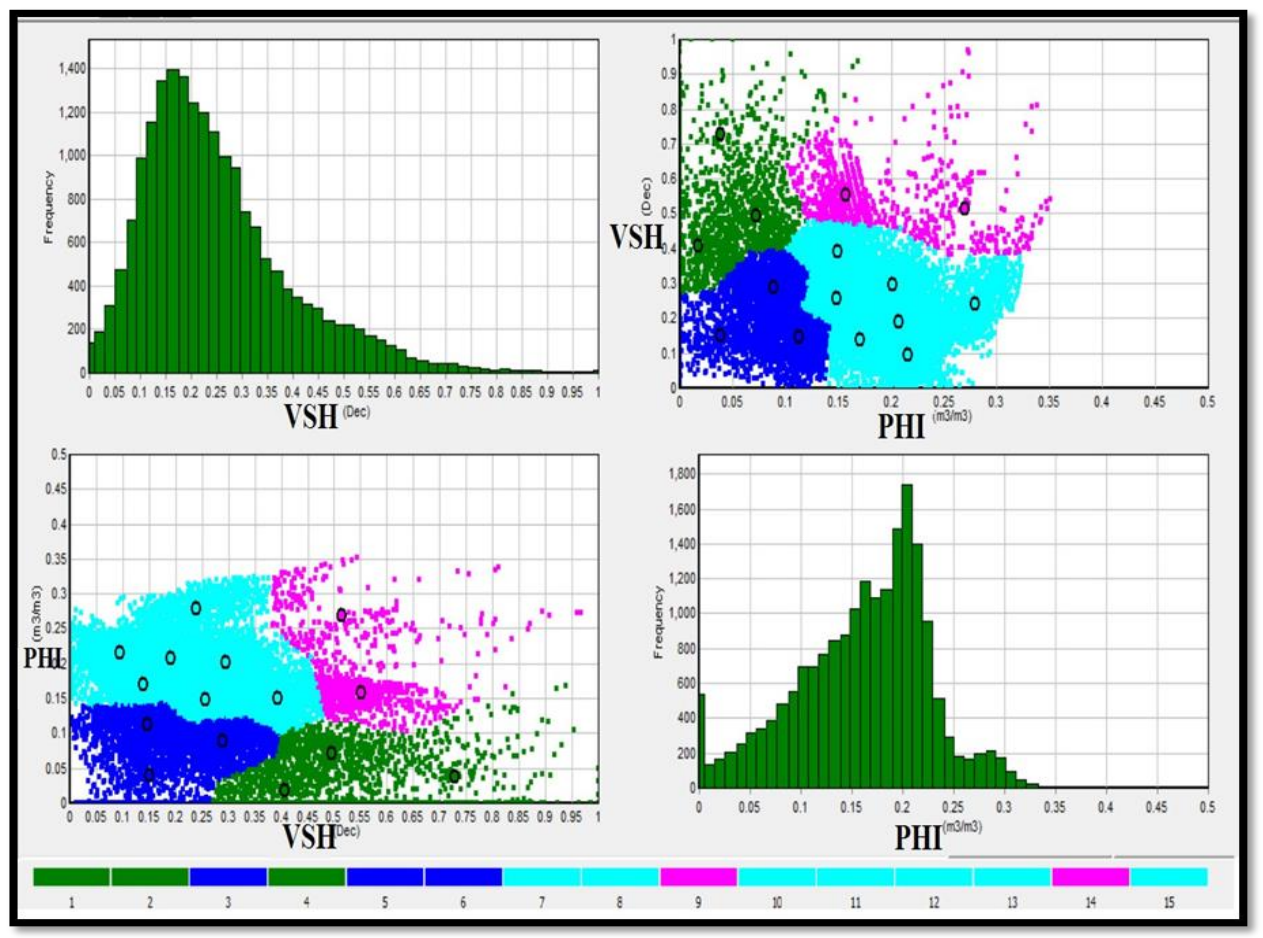

Fig. (7) Final graphical results of clustering analysis which show the relation between porosity and shale volume.

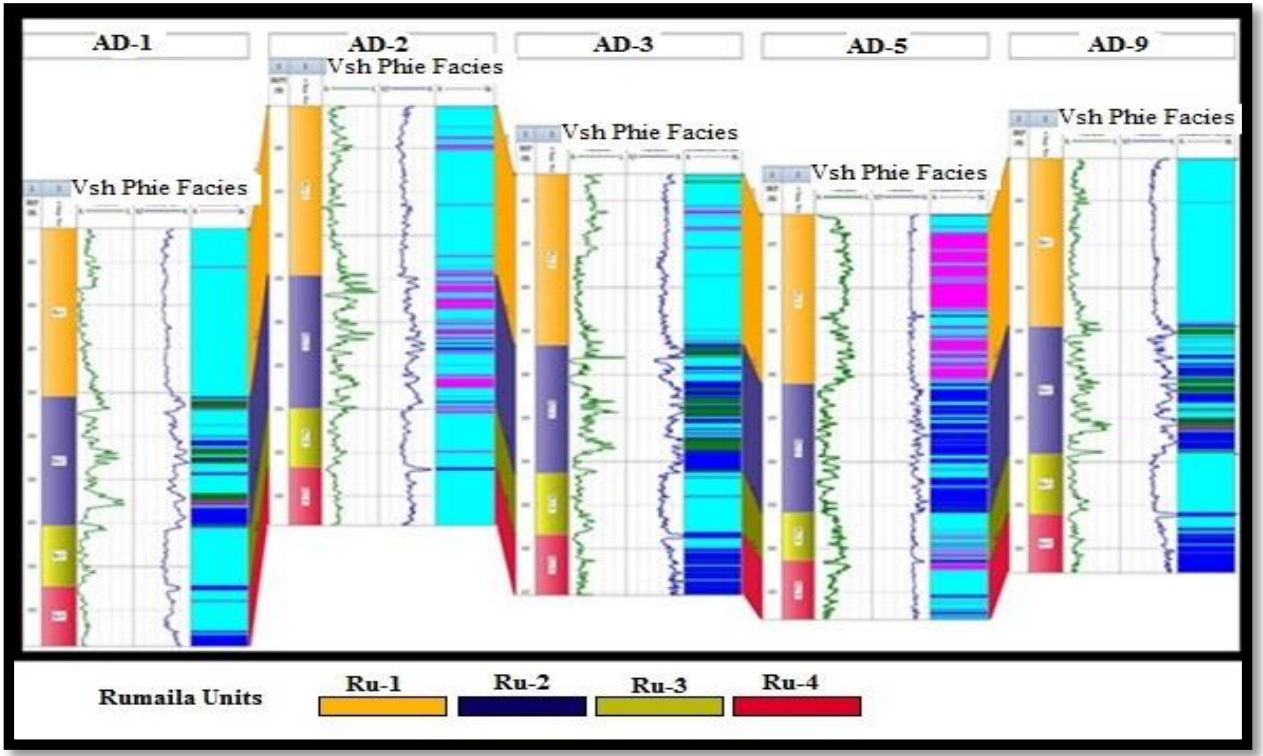

Fig. (8) Porosity and shale volume section and vertical distribution of rock types for wells AD-1, 2, 3, 5 and 9 in Rumaila Formation. 


\section{Journal of Petroleum Research and Studies}

Open Access

No. 31, June 2021, pp.49-73

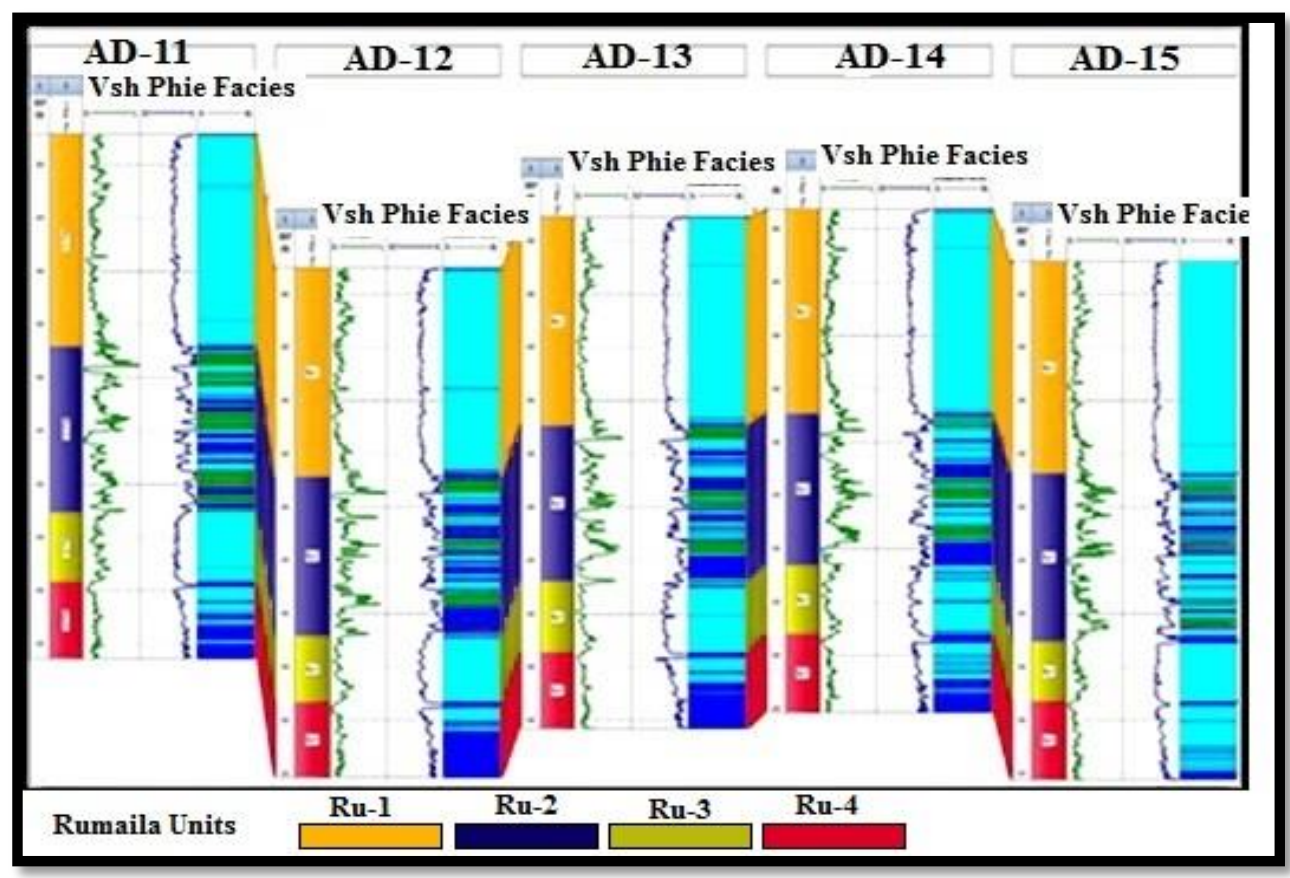

Fig. (9) Porosity and shale volume section and vertical distribution of rock types for wells AD-1, 2, 3, 5 and 9 in Rumaila Formation.

The units of Rumaila Formation are characterized by the following:

\section{Unit Ru-1}

It is the highest oil-bearing unit. This unit consists of packstone and grainstone facies due to consists mainly of rock type -2 that represents the highest percent about $95 \%$ from this unit as well as 5\% of wackstone to packstone of rock type-3 distributed near to well AD-15 at northern dome, Figure (10).

\section{Unit Ru-2}

The unit is characterized by major differences and variations in Facies which consists mainly of rock type- 2 about $38 \%$ and change to rock type-1 about $28 \%$ with $28 \%$ mudstone facies of rock type-4 as well as 5\% of rock type -3 . This unit represents morally bad facies in all domes of Ahdeb field, Figure (11). 


\section{Unit Ru-3}

Represents the second good unit in Rumaila Formation which consists mainly of packstone and grainstone of rock type- 2 with a small percentage of rock type -1 and rock type-3 especially near the well AD-5 at northern dome. According to distribution of rock type, this unit is oil bearing unit in Rumaila Formation especially at southern dome, Figure (12).

\section{Unit Ru-4}

This unit is fair oil bearing unit which becomes moderate rock type towards southern dome but becomes bad facies towards northern dome. It is characterized by wackestone to packstone facies which range from rock type- 2 about $56 \%$ to rock type -1 about $42 \%$ and $2 \%$ of rock type-3, Figure (13).

Figure (14) shows the vertical rock type distribution model using vertical cross section in the rock type model for Rumaila Formation included the Ahdeb wells. This section was taken along axes of southern and northern domes of Ahdeb field toward SENW direction in order to shows the rock type variations and all side changes along Ahdeb model. 
Open Access

No. 31, June 2021, pp.49-73

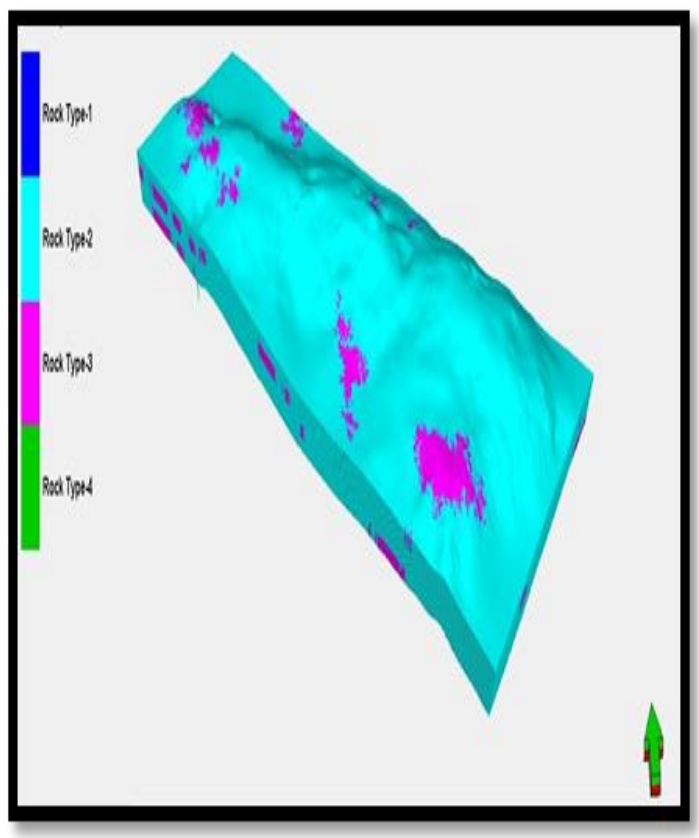

Fig. (10) 3D Rock type model for unit Ru-1 at Ahdeb field.

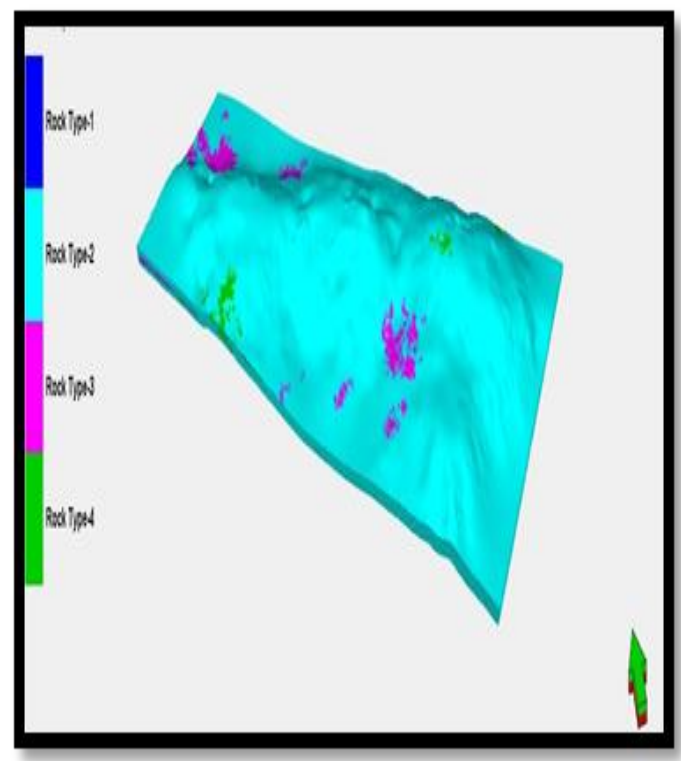

Fig. (12) 3D Rock type model for unit Ru-3 at Ahdeb field.

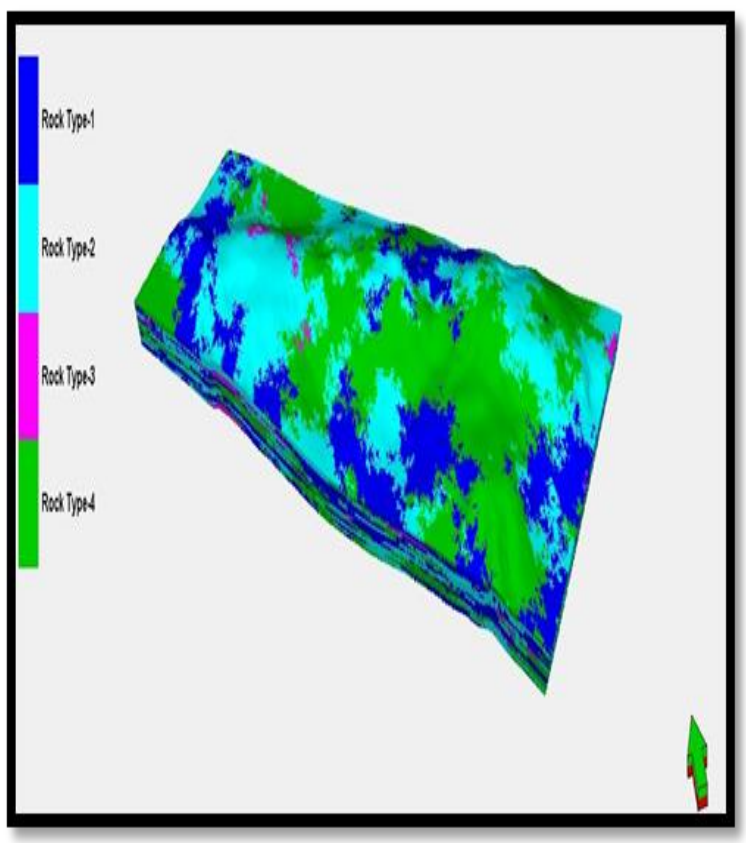

Fig. (11) 3D Rock type model for unit Ru-2 at Ahdeb field.

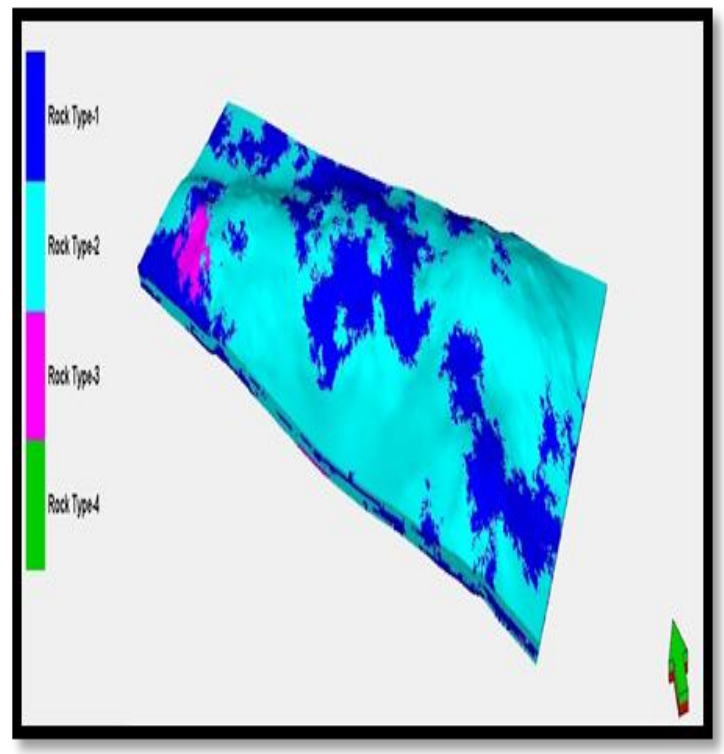

Fig. (13) 3D Rock type model for unit Ru-4 at Ahdeb field. 


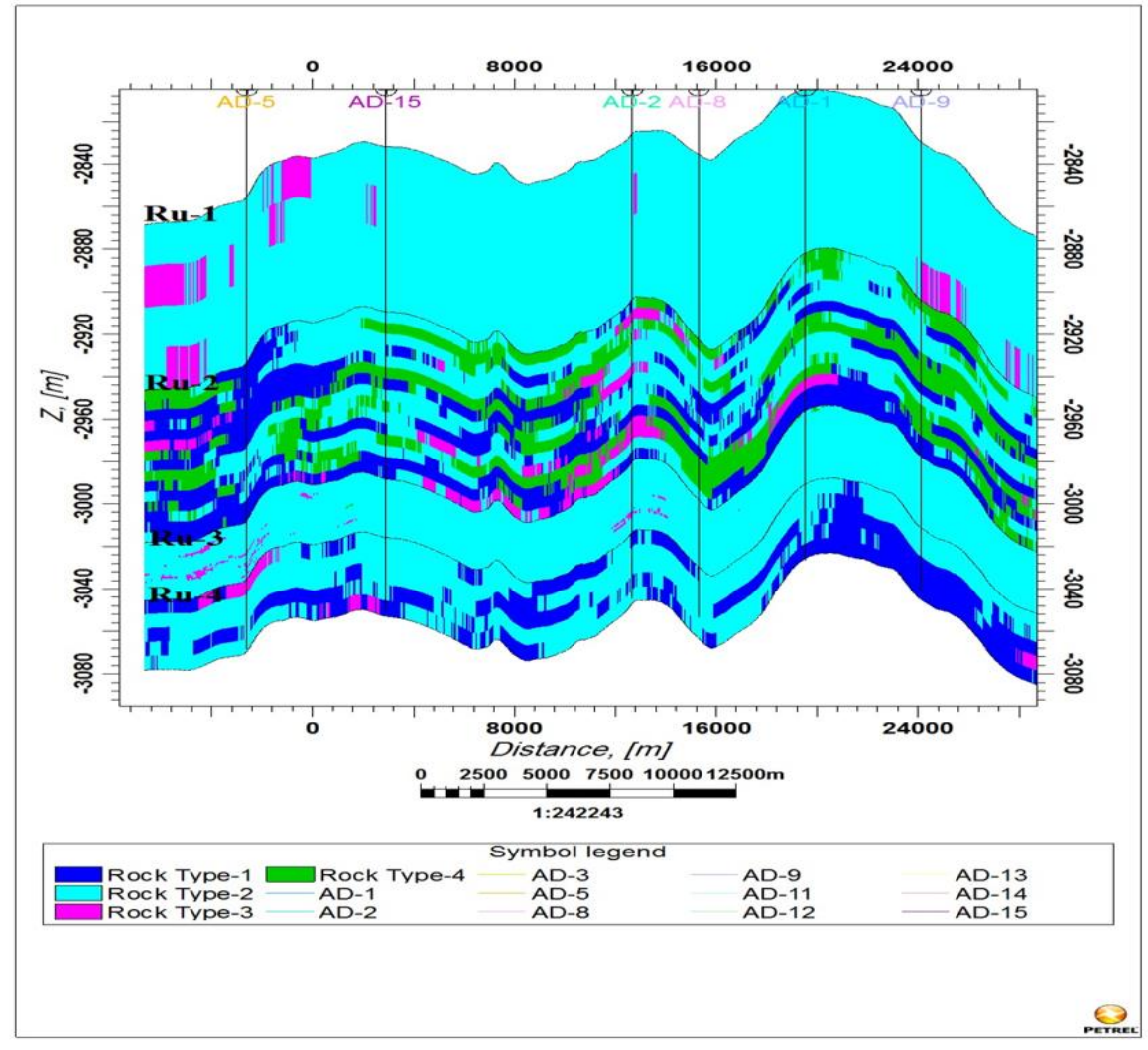

Fig. (14) Vertical cross section along SE-NW in 3D rock type model of Rumaila Formation.

\section{Conclusions:}

The function of multivariate cluster analysis based on response well logs determination has been documented in this study by comparing with thin section examination. Based on different cutoff levels, a desirable number of logfacies for any given formation has been achieved. Rock type construction represents the essential method to deduce the log-facies based on well logs data when the core and cutting is absent in drilled wells. The Cluster Analysis technique is a useful method to classify the 
available well log data into many clusters and then to groups. These groups have similar characteristics and represent each one is log facies.

The Rumaila Carbonate Reservoir, depending on the Microfacies and Electrofacies Character, the pattern for well logs, Porosity and cluster analytical process, was divided into four units and rock types.Four rock types were classified based on cluster analysis; those categories are: Type 1 rock was poor-black, Type 2 represented a very good form of calcareous rock (aqua color), Type 3 rock was a fair to good type of calcareous rock (Fuchsia colour) and Type 4 rock was a bad rock.3D rock type model is built by using Petrel software and depending on log-facies and microfacies analyses which are deduced by cluster analysis technique after classification of porosity and shale volume. This model showed that the limestone rock type- 2 that deposited in middle ramp is the essential oil-bearing facies at units Ru-1 and Ru-3 of Rumaila Formation. 


\section{Journal of Petroleum Research and Studies}

Open Access

No. 31, June 2021, pp.49-73

\section{References:}

[1] Serra, O., Fundamentals of well log interpretation. The interpretation of logging data, Elsevier, Amsterdam, Vol. 2, (1986).

[2] Gill, D., Shomrony, A., Fligelman, H., Numerical zonation of log suites and logfacies recognition by multivariate clustering. AAPG Bull. 77(10): 1781-1791, (1993).

[3] Al-Qenae KJ, Al-Thaqafi SH, New approach for the classification of rock typing using a new technique for iso-pore throat lines in Winland's Plot. Society of Petroleum Engineers, (2015).

[4] Riazi Z., Application of integrated rock typing and flow units' identification methods for an Iranian carbonate reservoir. J Pet Sci Eng 160:483-497, (2017).

[5] Al-Baldawi, B. A. H., Using Well Logs Data in Logfacies Determination by Applying the Cluster Analysis Technique for Khasib Formation, Amara Oil Field, South Eastern Iraq. Journal of Petroleum Research \& Studies (JPR \& S), No.12: 926pp, (2016).

[6] Al-Baldawi, B. A. H., Assessment of reservoir properties and Buckles model for Rumaila Formation in Ahdeb oil field, Central Iraq. Modeling Earth Systems and Environment (2020) 6:1683-1693, Springer Nature Switzerland.6 (3), (2020).

[7] Al-Ameri T. K., Al-Ekabi A. H., Al-Jawad S. N., Palynomorph stratigraphy, palynofacies and organic geochemistry assessments for hydrocarbon generation of Ratawi Formation, Iraq. Arab J Geosci 7(4):1433-1455, (2014).

[8] Al-Al-Baldawi, B. A. and Nasser, M. E., Evaluation of Petrophysical Characteristics of Carbonate Mishrif Reservoir in Ahdeb oil Field, Central Iraq. Iraqi J Sci 60(2): 321-329, (2019).

[9] Deng, H., Fu, M., Huang, T., Gluyas, J. G., Tong, M., Wang, X., Zhou, W., and Liu, F., Ahdeb Oil Field, Mesopotamian Basin, Iraq: Reservoir architecture and oil 
charge history, AAPG Bulletin, published online doi: 10.1306/0424181617217089, (2018).

[10] Bellen, R. C., Dunnigton, H. V., and Wetzel, R. and Morton, D. M., Lexique Stratigraphique international: 03 10Asie (Iraq), 333p, (1959).

[11] Buday, T., The Regional Geology of Iraq. Vol.1: Stratigraphy and Paleogeography. Publications of GEOSURV, Baghdad, (1980).

[12] Jassim S. Z., and Goff J. C., Geology of Iraq. Dolin, Prague and Moravian Museum, Brno. 341p, (2006).

[13] Tavakoli V, Amini A., Application of multivariate cluster analysis in logfacies determinationand reservoir zonation, case study of Marun Field, South of Iran. JSUT 32(2):69-75, (2006).

[14] Dresser Atlas, log Interpretation Charts. Houston. Dresser Industries, Inc., 107p, (1979).

[15] Schlumberger, Log Interpretation, vol.II - Applications: New York, (1974).

[16] Selley, R. C., Elements of Petroleum Geology, Academic Press, London, United Kingdom, 470p, (1998).

[17] Asquith, G. B. and Krygowski, D., Basic Well Log Analysis, 2nd Edition: AAPG Methods in Exploration Series 16. Published by The American Association of Petroleum Geologists Tulsa, Oklahoma, 244p, (2004).

[18] Schlumberger, Cased Hole Log Interpretation Principles/Applications, Houston, Schlumberger Wireline and Testing, 198p, (1998).

[19] Al-Baldawi, B., A., Applying the cluster analysis technique in logfacies determination for Mishrif Formation, Amara oil field, South Eastern Iraq. Arab J Geosci.8(6): 3767-3776, (2015).

[20] Sameer Noori Al-Jawad and Afrah Hassan Saleh., Flow units and rock type for reservoir characterization in carbonate reservoir: case study, south of Iraq. Journal of Petroleum Exploration and Production Technology. doi:10.1007/s13202-0190736-4, (2019). 